Article

\title{
Urban Multilingualism and the Civic University: A Dynamic, Non-Linear Model of Participatory Research
}

\author{
Yaron Matras * and Alex Robertson \\ School of Arts, Languages and Cultures, University of Manchester, Manchester, M13 9PL, UK; \\ E-Mails: yaron.matras@manchester.ac.uk (Y.M.), alex.robertson@manchester.ac.uk (A.R.) \\ * Corresponding author
}

Submitted: 16 August 2017 | Accepted: 16 October 2017 | Published: 22 December 2017

\begin{abstract}
Drawing on the example of Multilingual Manchester, we show how a university research unit can support work toward a more inclusive society by raising awareness of language diversity and thereby helping to facilitate access to services, raise confidence among disadvantaged groups, sensitise young people to the challenges of diversity, and remove barriers. The setting (Manchester, UK) is one in which globalisation and increased mobility have created a diverse civic community; where austerity measures in the wake of the financial crisis a decade ago continue to put pressure on public services affecting the most vulnerable population sectors; and where higher education is embracing a neo-liberal agenda with growing emphasis on the economisation of research, commodification of teaching, and a need to demonstrate a 'return on investment' to clients and sponsors. Unexpectedly, perhaps, this environment creates favourable conditions for a model of participatory research that involves co-production with students and local stakeholders and seeks to shape public discourses around language diversity as a way of promoting values and strategies of inclusion.
\end{abstract}

\section{Keywords}

language; Manchester; multilingualism; participatory research; social responsibility; university

\section{Issue}

This article is part of the issue "Multilingualism and Social Inclusion", edited by László Marácz (University of Amsterdam, The Netherlands/Gumilyov Eurasian National University, Kazakhstan) and Silvia Adamo (University of Copenhagen, Denmark).

(C) 2017 by the authors; licensee Cogitatio (Lisbon, Portugal). This article is licensed under a Creative Commons Attribution 4.0 International License (CC BY).

\section{Introduction}

The years 2016-2017 brought about a new intensity of political campaigns that challenge notions of globalisation and purport to address inequality. To be sure, globalisation created challenges even where its most obvious beneficiaries - those whom Goodhart (2017) terms 'Anywheres' on account of their mobile, achieved identityare concentrated, namely in cosmopolitan urban centres: Global cities (Sassen, 2005) have been trialled to maintain cohesion among increasingly diverse populations (Finney \& Simpson, 2009), to reap the benefits of the 'diversity dividend' (Syrett \& Sepulveda, 2011), and to embrace diversity as a political model of managing difference (Schiller, 2016). At the same time, the city of the future is viewed as a site where traditional forms of governance must give way to ever-permeating networks of partnership (Amin \& Thrift, 2017). The study of urban multilingualism tended to focus initially on descriptive inventories of language communities that share urban space (e.g., García \& Fishman, 1997), on community language policy (e.g., Clyne \& Kipp, 2006), and on methods of mapping language vitality (e.g., Barni \& Extra, 2008), but it has since shifted its attention to practices and ideologies that call for novel conceptualisations of multilingual repertoires (Blommaert, 2010; Canagarajah, 2017; García \& Wei, 2014; Heller, 2011; Pennycook \& Otsuji, 2015), new participatory methods of investigation (Cadier \& Mar-Molinero, 2012; Stevenson, 2017), and new challenges for policy especially around issues 
of inclusion and social justice (Piller, 2016; cf. also Matras, 2017).

Such questions often prompt practical considerations as to how research can help empower actors to embrace as legitimate everyday practices pertaining to their multilingual identities in an environment that continues to be dominated by monolingualist, nation-state oriented narratives and policy measures (cf., Arnaut, Blommaert, Rampton, \& Spotti, 2016; Blackledge \& Creese, 2010). One of the earliest examples of research-led policy initiatives is the Research Unit for Multilingualism and Cross-Cultural Communication, founded in 2001 by Michael Clyne (1939-2010) at the University of Melbourne to promote networking around community language policy and bilingual education. At the University of Edinburgh, Antonella Sorace founded Bilingualism Matters, an initiative devoted to promoting awareness of the cognitive benefits of bilingualism, especially for children, through research, training and consultancy. While a comprehensive survey of university engagement around urban multilingualism is beyond the scope of this paper, we refer to Malinowski (2016) for an example of how undergraduate teaching in Applied Linguistics can be made 'locally meaningful' by using the urban environment and its linguistic landscape as a setting for research-led learning, introducing an aspect of community awareness into the curriculum.

The Multilingual Manchester (MLM) research unit at the University of Manchester was launched in 2010 and has since been cited as an example of good practice by several authors, among them Rampton (2015) on project-led teaching, research, and civic engagement at university level; Bracken, Driver and Kadi-Hanifi (2016, pp. 137-138) on introducing language diversity into the school curriculum and inclusion agenda; Tietze, Holden and Barner-Rasmussen (2016, pp. 315-316) on the effects of language diversity on the local economy; Lucas (2016, p. 92) on the relevance of diversity to social work; and King (2015, pp. 187-188) on shaping local policy discourse on language diversity. Key aspects of MLM's work have been replicated at various research-intensive universities around the world including Graz (Multilingual Graz, n.d.), Melbourne (Multilingual Melbourne, n.d.) and NTU Singapore. These citations prompt us to recount the considerations and strategies that led to the initiative and to engage in a critical reflection on the way in which challenging circumstances can bring about creative solutions, as well as on the pressures and risks that are part of the package.

\section{The Social Setting}

Manchester is one of the world's first industrial cities and its social fabric has been shaped by waves of immigration since the mid-19th century. The post-war and postcolonial period saw immigrants from Eastern Europe, former colonies in South Asia, East Asia and the Caribbean, migrants and refugees from the Middle East and Africa and EU-migrants settling in the city. Drawing on a triangulation of datasets and observations (Matras \& Robertson, 2015) we believe that currently between 150-200 languages are spoken in the city among a population of some 530,000 residents. In the national Census of 2011, 16.6\% of Manchester's residents-twice the national average-reported having a 'main language' other than English, while in 2015-2016 some 37\% of school pupils were registered as having a non-English 'first language'. The largest language groups-Urdu, Panjabi, Chinese, Arabic, Polish, Bengali, Somali, Kurdish-give an indication of the city's language diversity (Greater Manchester is also home to one of the world's largest Yiddishspeaking communities).

The city flags its commitment to inclusion, equality and diversity in various documents such as the biannual 'State of the City: Communities of Interest' report and in mission statements of key strategic institutions such as the Communities and Equalities Scrutiny Committee, Manchester's Inwards Investment Agency (MIDAS) and the Manchester Forum. As part of this commitment, public services maintain various language provisions: The City Council has its own in-house translation and interpreting service; Central Manchester Hospitals, one of three main hospitals in the city, responds to around 48,000 interpreting requests annually for 100 different languages; and city-run libraries issue around 70,000 titles in languages other than English. The city's landscape features commercial signs in more than 50 languages and at least 40 community-run supplementary (weekend) schools teach community languages.

Following industrial decline in the late 1980s Manchester began to embark on a regeneration effort, adopting a so-called 'entrepreneurial urban governance' approach that regarded social cohesion not just as social justice, but as a way to boost competitiveness. It delegated planning and delivery to partnerships with the private sector and local communities and gave them a voice in governance bodies, seeking to promote a metropolitan identity that emphasised the city's diverse and cosmopolitan character (cf., Peck \& Ward, 2002; Williams, 2003; Young, Diep, \& Drabble, 2006). The introduction of austerity measures in 2010 saw a severe reduction in local authority budgets and an increase in the outsourcing of advice and support services to private and third (nonprofit) sector providers, especially around activities to facilitate access to key services for disadvantaged groups. The healthcare and judicial sectors now rely largely on private contractors for interpreting and translation services, while schools often rely on private and third sector initiatives for classroom support such as bilingual assistants and cross-cultural training.

\section{The University Environment}

In 2010, the Higher Education Funding Council for England (HEFCE) introduced 'non-academic impact' into the metrics of the Research Excellence Framework (the pe- 
riodical mechanism for assessing universities' research performance). Research Councils UK (RCUK), which brings together the country's public research funding bodies, defines non-academic impact as the demonstrable contribution that research makes to society and the economy', measured in terms of 'fostering global economic performance, and specifically the economic competitiveness of the UK, increasing the effectiveness of public services and policy, enhancing quality of life, health and creative output' (RCUK, n.d.). In the latest assessment exercise in 2014, universities were required to submit a number of impact case studies proportional to the number of research-active staff, as public debate highlighted non-academic impact as a way of guaranteeing a return on the state's investment in research. The new procedure coincided with the raising of university annual tuition fees to $£ 9,000$, a move that was defended by referring to graduates' higher earning potential coupled with the argument that society as a whole should not have to pay for the economic advantage gained by individuals.

These two measures introduced significant changes to the country's higher education environment, strengthening trends toward the economisation of research (measuring success in terms of revenue to the university and economic benefit to society) and the commodification of teaching. The metrics of the new Teaching Excellence Framework, introduced in 2017, are expected to rate universities more strongly than ever before on the basis of student satisfaction surveys, the academic level of entrants, and graduates' success in finding highly skilled employment ('positive graduate destinations'); universities that score high are expected to be allowed to raise tuition fees even further. This has already led to a wave of structural changes among some universities in England to replace staff and reduce degree programmes predicted to be 'unsustainable' in relation to the new criteria.

To meet expectations of impact and graduate employability, universities had long begun to engage in regional development programmes (cf., Chatterton \& Goddard, 2000). For the Arts and Humanities, where demonstrating impact on policy and society is seen as particularly challenging, Comunian, Gilmore and Jacobi (2015) embrace the term 'creative economy' to designate the interplay of knowledge and cultural production with economic processes and propose a model of knowledge transfer in which universities provide 'third spaces' where regional exchange and collaboration networks with and among external partners can be developed. In relation to teaching and learning, universities around the globe have been embracing models of Social Responsibility that aim to educate students toward active citizenship by creating community partnerships and leadership schemes (see Shek \& Hollister, 2017). Buffel, Skyrme and Phillipson (2017, p. 201) describe the University of Manchester as the first of England's 'civic universities', founded in the 19th century with an explicit mission to serve the regional economy and culture. They draw a connection between this history and the institution's current mission statement, describing how in 2012 it adopted Social Responsibility as one of its three core goals alongside Teaching and Research. They go on to describe a research co-production model on Ageing, which develops links with local interest groups, trains older people from the community as co-investigators, and organises dissemination events with local stakeholders. The project opens a pathway to impact by involving policy actors in the research design and through targeted dissemination to policymakers and practitioners. Leggio (2017) reports on another co-production project based at the University of Manchester-MigRom (n.d.) - where researchers worked in partnership with members of the local community of Roma migrants from Eastern Europe and the local authority to support social inclusion. Leggio describes how the project empowered its Roma participants through what Harney, McCurry, Scott and Wills (2016) define as a 'process pragmatism' approach to participatory research that embeds knowledge production in reciprocal relationships and creates alliances to facilitate action.

\section{MLM: The Launch of a Non-Linear Model of Participatory Research}

'Process pragmatism' is a distinct approach to coproduction that views research itself as part of a process of social change. Rather than engaging in inquiry around a pre-determined problem, its guiding principle is to bring together different groups of people to find common ground and then, through this mode of participatory inquiry, to identify issues for investigation, building on these relationships (Harney et al., 2016, pp. 318-324). This approach lends an interpretation to the notion of 'participation' that differs from Participatory Action Research (Cameron \& Gibson, 2005; Cox, 2015), where external stakeholders are invited to use academic space as a platform for mobilisation. Instead it adopts a somewhat flexible position on a continuum of models ranging from partnerships that serve tokenistic functions, to those that are genuinely transformative of participants' practices. Common to most of these models is nonetheless a need to define the position of non-academic partners in relation to the power that academics maintain over their own space: Participation is seen either as 'invited' and thus aimed at facilitating research, or as 'reclaimed' and geared toward transferring power over academic space to others (cf., Cornwall, 2008, pp. 275-281).

MLM offers a different kind of participatory model, where the question of ownership is revisited thanks to the inherently reciprocal nature of the process. Engagement-oriented academic models are typically characterised by linearity, whereby teaching is informed by research, research is facilitated by access to data and observation settings, impact and knowledge exchange are derived from research, and external stakeholders are 
invited into the academic space. Social responsibility is regarded as an overarching ethos that guides the university's overall contribution to society, for instance by setting good practice standards for environmental sustainability or equality and diversity, and in some cases through practices like applied research and student volunteering (cf., Shek \& Hollister, 2017). MLM breaks this linearity and replaces it with a dynamic relationship, where teaching and learning enable student research that can have its own impact, issues articulated by stakeholders can guide research, student volunteering can offer an observation setting, and initiatives for mobilisation and social change can come from academics and be taken up by external stakeholders. In this way, the common division of roles between researchers, students, and non-academic stakeholders gives way to an organic process in which various actors have ownership of different activities at different times, and their cumulative contributions gradually develop into a theme-based and purpose-oriented network.

The Commonwealth Games, held in Manchester in 2002, gave the city's image a significant boost. During the decade between the two Censuses in 2001 and 2011, Manchester recorded the highest growth of a young population in England. Thanks to a merger and re-structuring in 2004, the University of Manchester became the country's largest single-site university, winning a significant government investment in infrastructure and attracting record year on year growth in student numbers. MLM was born in response to growing class sizes, benefitting from new opportunities for digital learning and the emerging Social Responsibility agenda: around 150 students enrolled in 2009 in a new second year undergraduate module on Societal Multilingualism. In order to effectively manage creative assessment, students were guided to conduct group projects on any aspect of multilingualism in Manchester. The pilot introduction of a digital platform for coursework submission in the same year offered an opportunity to archive project reports, and a grant of $£ 1,000$ from the first round of the University's Social Responsibility in the Curriculum scheme enabled the design of a keyword-searchable website. Eight years on, this online archive contains around 130 project reports authored by some 500 undergraduate studentsthe largest online archive of original work on multilingualism in any city and in all likelihood the largest online research archive authored exclusively by undergraduate students (Multilingual Manchester, n.d.-a). The published reports attracted the attention of local schools and the National Health Service, which approached the MLM team with requests for guidance on local language communities. The principle was thus born of communitybased student research triggering interest from stakeholders and leading to collaborative ventures with a potential for high-impact research. That very model was written into the course unit description, flagging employability skills in the area of 'diversity management' such as gaining awareness of population diversity, developing tools to assess the needs of diverse communities and strategies to assess existing provisions. Students were advised that such skills are high in demand in a variety of sectors and that projects offered opportunities for practical research work in the local community as well as a unique opportunity to disseminate insights to wide external audiences.

MLM's branding strategy was drafted in July 2009 with the help of the University's Directorate for Business Engagement and External Relations, with the explicit goal of setting up a centre with potential for high-impact research, public engagement and community outreach. Conversations with University managers about an organisational framework stalled, however, and a launch event with local stakeholders did not take place until October 2010. In February 2012, MLM created an interactive exhibition at Manchester Museum, which was documented in an online video ${ }^{1}$ and received enthusiastic feedback. With the launch of a new University agenda to 'enhance the student experience' as well as a new Universityinternal Social Responsibility Strategic Investment Fund, MLM received a small grant in January 2013 to support part-time student research. This resulted in a comprehensive and ground-breaking report on language communities and language provisions in Manchester (Gopal, Matras, Percival, Robertson, \& Wright, 2013), an accompanying fact sheet and video, a stakeholder event with local public services, and the launch of the University of Manchester's very first theme-based student volunteer scheme (see below). In July 2015, the University made a 3-year award to cover a full-time staff position, which quickly helped boost successful external grant capture from the national research councils ESRC, AHRC and British Academy. In February 2016, MLM launched LinguaSnapp, the University of Manchester's very first smartphone application for teaching and research, designed to document images of multilingual signage (Multilingual Manchester, n.d.-b). Students have used the application for original coursework research; the app has been included in Manchester City Council's online portal as one of just two external sources on data and intelligence, and versions have been rolled out to other cities including Melbourne and Jerusalem.

\section{A Social Inclusion Agenda}

The launch of the University of Manchester's Social Responsibility goal featured internal discussions about ways to identify performance indicators around the chosen motto 'Making a Difference'. What makes MLM distinct is that both its research and public engagement are guided by a vision of the way in which appreciation of language diversity can make a difference toward a more inclusive society. This vision identifies three principal pillars: First, language provisions are a key to Access (to services such as health and education, to employment, to

\footnotetext{
$\overline{1}$ https://www.youtube.com/watch?v=dwC_rfpcKrA
} 
social networks and to media and information). Removing barriers to access is the first step toward ensuring social equality. From a planning perspective, the process requires tools for needs assessment and an evaluative overview of models of good practice for the delivery of provisions (such as interpreting and translation services, support for learning English as additional language, and more). Next, languages represent cultural Heritage, the protection of which is key to ensuring community cohesion and building confidence within and among communities. Exploring and documenting language heritage and equipping communities with the tools to safeguard their heritage support inclusivity and help counter marginalisation. Finally, in a globalised economy, languages are key Skills that open up opportunities for growth and development. By cultivating awareness of the skills potential of knowing languages (including home or heritage languages) and developing strategies to harness those skills, civic communities can reap a 'diversity dividend' (Syrett \& Sepulveda, 2011) and make the heritage of minority groups work for the benefit of the majority.

Collection, analysis and triangulation of data are central to profiling Manchester's multilingualism and understanding the language needs of the city's communities. In the MLM model, this process takes a number of shapes. It can be, for example, student-led: the above-mentioned student reports present a range of data on language use in various domains. Student groups sometimes draw on specific knowledge of a language, a neighbourhood, an institution or a technical method to collect their data, which lends a unique insight to their analysis. In 2013, MLM developed a survey tool to record data on the home languages of schoolchildren, having identified limitations of the official School Census. The School Language Survey was piloted initially by a student group as part of their assessed coursework, which provided an opportunity to test the method before the MLM team undertook a wider pilot study (Matras, Robertson, \& Jones, 2016). Since, students of other disciplines and teachers have been trained in the method. In 2015, the team published a report based on interviews with staff and pupils from community-run supplementary schools, which flagged communities' commitment to maintaining linguistic and cultural heritage (Gaiser \& Hughes, 2015). The data provide insight into the skill potential of the next-generation workforce. The interview process helped to establish a collaborative network of contacts, which is still active. MLM research has also been responsive to questions of interest raised by local stakeholders. In 2014, NHS Manchester co-sponsored research into language provisions and access to healthcare (Gaiser \& Matras, 2016). LinguaSnapp, launched in 2016, offers an opportunity for public and student involvement in data collection, while the Language Data Tool, currently under development, will allow public users to query datasets relating to languages in Manchester and visualise them geographically, responding to the vision of the future city as a 'smart city' where networks of actors pool data (cf., Amin \& Thrift, 2017).
Each year, over 200 students from different academic disciplines register to participate in MLM's student volunteering scheme. Volunteers offer practical support to the work of host institutions, largely in the public and community sectors. At the same time, they benefit from a unique insight into the challenges facing service providers in a multilingual city and the opportunity to learn more about the experiences of other residents and about Manchester's diverse communities. Students often report that the scheme is not only academically stimulating and useful for employability, but also offers them a new perspective on the city. Projects range from accompanying interpreters to record patient experience testimonies of non-English speakers at Central Manchester Hospitals, delivering weekly English conversation sessions for refugees and new arrivals at local community centres, and gathering public feedback on and redrafting letters that Greater Manchester Police uses to communicate with victims of crime (Multilingual Manchester, n.d.-c). The design of these activities often emerges in early discussions with organisations about their practices and the challenges that face them; sometimes, as in the example of Greater Manchester Police, a request for practical support in improving service delivery is a point of departure and the resulting student volunteering activity provides an immediate, flexible response that leads to and cements longer-term engagement and opportunities for collaborative research.

In February 2017, MLM launched a Supplementary School Support Platform as a way of offering curriculum enrichment activities, training, networking opportunities and help with logistical issues to community-run language schools. A network of supplementary schoolteachers from schools teaching different languages meets on a semi-regular basis with the MLM team to share experiences and jointly design activities. Scientists from the University deliver interactive sessions in the community language, exposing pupils to new uses of their language, introducing the University, and broadening researchers' community engagement opportunities.

Language documentation itself opens up new avenues to support people in defending their civil liberties and creates pathways for inclusion. The Kurdish (Multilingual Manchester, n.d.-d) and Arabic (Multilingual Manchester, n.d.-e) databases have potential to shift the parameters in supporting refugees and their legal representatives to scrutinise decisions in cases involving Language Analysis for Determination of Origin, where public policy and practice has often come under professional criticism (cf., Patrick, 2012). Training delivered to practitioners in the public sector on risk management in interpreting has drawn on research to support front-line service providers in making their provision more inclusive.

In this way, the civic university can play a role in alleviating the pressure on resources and gaps in provision caused by austerity, and contribute directly to social inclusion by empowering disadvantaged groups, improving communication, and nurturing a generation of gradu- 
ates who are sensitised to social inclusion themes. It also has a role in shaping public discourses on language and as a broker of good practice. MLM's cross-sector workshops have involved representatives from local authorities, the health and judicial sectors, community organisations, schools, supplementary schools, and more. Levenshulme Language Day, a multi-venue, family-friendly community event to celebrate language diversity, has attracted many hundreds of local residents. ${ }^{2}$ Such events have inspired the gradual consolidation of a city narrative on policy and planning around the theme of languages (Multilingual Manchester, n.d.-f).

Raising confidence is an important key to social inclusion. MLM's targeted events with particular audiences have helped build confidence around heritage languages. Activities with schoolchildren and families offer opportunities to enter into wider partnerships with external stakeholders including public sector practitioners and private sector organisations: NHS speech and language therapists approached MLM to create a resource, for use by practitioners, that could give confidence to parents raising their children in multilingual homes; the team engaged student volunteers to make a short film that features local families offering guidance based on their experience. ${ }^{3}$ An education project delivered in collaboration with Community Rail Lancashire saw primary school pupils create artwork featuring community languages for display in a local train station. ${ }^{4}$

\section{Managing Risks}

Buffel et al. (2017, p. 213) identify a number of risks of the co-production strategy, notably the time commitment from researchers needed to coordinate a collaborative and participatory project with multiple partners, the need to negotiate power relationships between different stakeholders, and the fact that co-production might raise expectations about the implementation of possible solutions to problems. Leggio (2017) raises further issues, discussing the challenges encountered by the MigRom project when it sided with its Roma participants in formulating a critique of narratives that were being disseminated by an organisation with close links to the project partner, Manchester City Council, thereby testing the stability of the partnership (see also Matras \& Leggio, 2017). All these can be considered 'external' risks, which arise through dealing with stakeholders that are based outside the higher education sector. MLM's participatory research strategy shares some of these risks, and demonstrates others as well, including some that are 'internal'.

Expectations from stakeholders that the activity can provide longer-term solutions to service gaps (for example, recording patient experience or providing English conversation support) risk creating a form of dependency. At the same time, the University's engagement in a form of service provision risks being seen by third sector agencies that depend on service delivery contracts as competition, and this can be an obstacle to a fruitful relationship with such organisations. Public sector agencies and their private contractors alike may regard the University's involvement in assessing provisions as a form of uninvited and therefore unwelcome scrutiny. External partners who are not yet thoroughly familiar with the University's public engagement agenda and with MLM's specific vision sometimes view its activities as driven primarily by a short-term interest in gaining access to research data and are not always appreciative of the sincerity of the commitment to engagement or of the genuineness of the 'Making a Difference' motto.

Internally, managing a student volunteer scheme in which students are relied upon to make a direct and sometimes essential contribution to the work of the host organisation brings with it responsibilities of pastoral care, for instance when students working in the health sector environment or those supporting refugees are exposed to moving personal stories that may be emotionally challenging, or feel a responsibility toward managing the learning progression of their pupils in English conversation sessions. Ironically, one of the biggest risk factors in MLM's work is its continuous dependency on the University's commitment to its Social Responsibility agenda and on short or middle-term investment from the University in dedicated support staff. Such dependency is inevitably accompanied by uncertainties as it is caught up in volatile processes of prioritisation and internal competition for resources.

A key to managing many of the external risks is the opportunity to demonstrate a long-term commitment to supporting stakeholders, involving partners in shaping performance indicators and milestones, and maintaining full autonomy of all parties in the partnership, especially by accommodating to the priorities and delivery modes set by host or partner institutions. Thus, student volunteers join activities on terms set by the host institutions and with a focus on the needs defined by the partners rather than in a form of either work experience or shadowing where the students themselves are primary beneficiaries; the support offered to supplementary schools derives from a two-year consultation process through which needs, priorities and operational approaches were identified. Pastoral care of student involvement is managed partly by prompting student participants to active reflection and feedback, and using veteran students as role models and facilitators. The time effort consideration noted by Buffel et al. (2017) is one of the key structural challenges. MLM currently maintains three fixedterm project managerial staff positions (in addition to research staff and academic lead) of which one is funded by the University and two from external grants. These are academically-related staff roles, for which training in the

\footnotetext{
${ }^{2}$ https://www.youtube.com/watch?v=|OfhRbxeHWI

${ }^{3}$ https://www.youtube.com/watch?v=8VJZ5ZCjIRg

${ }^{4}$ https://www.youtube.com/watch?v=Mkstv9Euw_Q
} 
relevant subject area and research experience are essential. Their task is to build and maintain long-term relationships of trust with external stakeholders and manage the complexity of placements, outreach, public engagement and publicity. Continuity is therefore key to the building of the reputational and practical capital that lends credibility to the 'Making a Difference' motto. But this rests primarily on the University's willingness to make a longterm commitment to providing core resources, on which competitive bids for research grants rely, and to recognise the value of specialised support staff whose roles are quite distinct from those of administrative managers.

\section{Concluding Remarks}

Models of 'process pragmatism' have benefited, as Harney et al. (2016, p. 326) note, from the move to encourage impact, knowledge exchange and public engagement in higher education. The structural opportunities provided to MLM reflect the drive to increase impact case studies in the Arts and Cultures, the need to demonstrate employability and innovative 'student experience' in order to attract fee-paying students, and the overall flagging of a Social Responsibility agenda. The initiative's institution-internal value is thus measured in response to pressures set by a changing funding environment. The activity's value to external stakeholders has, by contrast, a more perpetual nature, as the challenges and opportunities of language diversity to social inclusion are independent of higher education policy. Nonetheless, here too political developments such as austerity (the withdrawal of local authority structural support) and concerns over commitments (both ideological and material) to an inclusive society in the aftermath of the Brexit vote in 2016, create needs for practical as well as discursiveargumentative input. MLM's unique selling point is a participatory research model in which ownership of space is not linear, but revolves around concrete tasks that are shared and coordinated in a stable network of partnerships: Students own their research work, developed under guidance and through access to research sites; host institutions own the objectives and deliverables of student volunteer engagement and of co-produced research and public events; and the stability of partnerships based on such revolving ownerships opens up unique opportunities for the research team to develop insights of its own. The major challenge remains the need to reconcile continuity and stability, which is a prerequisite for the reputational capital on which the partnerships rest, with the institution's ability to maintain its practical commitment to the civic university vision.

\section{Acknowledgments}

The research leading to this contribution has been partly funded by a grant from the University of Manchester's Humanities Strategic Investment Fund for Social Responsibility as well as by a grant from the Arts and Humani- ties Research Council as part of the Open World Research Initiative consortium on 'Cross-Language Dynamics: Reshaping Community'.

\section{Conflict of Interests}

The authors declare no conflict of interests.

\section{References}

Amin, A., \& Thrift, N. (2017). Seeing like a city. Cambridge: Polity Press.

Arnaut, K., Blommaert, J., Rampton, B., \& Spotti, M. (Eds.). (2016). Language and superdiversity. London: Routledge.

Barni, M., \& Extra, G. (Eds.). (2008). Mapping linguistic diversity in multicultural contexts. Berlin: Mouton de Gruyter.

Blackledge, A., \& Creese, A. (2010). Multilingualism. London: Continuum.

Blommaert, J. (2010). The sociolinguistics of globalization. Cambridge: Cambridge University Press.

Bracken, S., Driver, C., \& Kadi-Hanifi, K. (2016). Teaching English as an additional language in secondary schools: Theory and practice. London: Routledge.

Buffel, T., Skyrme, J., \& Phillipson, C. (2017). Connecting research with social responsibility Developing 'agefriendly' communities in Manchester, UK. In D. Shek, T. L. Daniel, \& R. M. Hollister (Eds.), University social responsibility and quality of life. A global survey of concepts and experiences (pp. 99-120). Berlin: Springer.

Cadier, L., \& Mar-Molinero, C. (2012). Language policies and linguistic super-diversity in contemporary urban societies: The case of the City of Southampton, UK. Current Issues in Language Planning, 13(3), 149-165.

Cameron, J., \& Gibson, K. (2005). Participatory action research in a post-structuralist vein. Geoforum, 36(3), 315-331.

Canagarajah, S. (Ed.). (2017). The Routledge handbook of migration and language. London: Routledge.

Chatterton, P., \& Goddard, J. (2000). The response of higher education institutions to regional needs. European Journal of Education, 35(4), 475-496.

Clyne, M., \& Kipp, S. (2006). Australia's community languages. International Journal for the Sociology of Language, 180, 7-21.

Comunian, R., Gilmore, A., \& Jacobi, S. (2015). Higher education and the creative economy: Creative graduates, knowledge transfer, and regional impact debates. Geography Compass, 9(7), 371-383.

Cornwall, A. (2008). Unpacking "participation": Models, meaning and practices. Community Development Journal, 43(3), 269-283.

Cox, L. (2015). Scholarship and activism. A social movements perspective. Studies in Social Science, 9, 34-53.

Finney, N., \& Simpson, L. (2009). 'Sleepwalking to segregation'? Challenging myths about race and migration. Bristol: The Policy Press. 
García, O., \& Fishman, J. A. (1997). The multilingual apple. Languages in New York City. Berlin: Mouton de Gruyter.

García, O., \& Wei, L. (2014). Translanguaging: Language, bilingualism and education. London: Palgrave Macmillan.

Gaiser, L., \& Hughes, P. (2015). Language provisions in Manchester supplementary schools. Retrieved from http://mlm.humanities.manchester.ac.uk/wp-content /uploads/2015/12/Language-provisions-in-Manches ter-supplementary-schools.pdf

Gaiser, L., \& Matras, Y. (2016). Language provisions in access to primary and hospital care in central Manchester. Retrieved from http://mlm.humanities.man chester.ac.uk/wp-content/uploads/2016/09/Langua ge-provisions-in-access-to-primary-and-hospital-care -Sept-2016.pdf

Goodhart, D. (2017). The road to somewhere. The populist revolt and the future of politics. London: Hurst Publishers.

Gopal, D., Matras, Y., Percival, L., Robertson, A., \& Wright, M. (2013). Multilingual Manchester: A digest. Retrieved from http://mlm.humanities.manchester. ac.uk/wp-content/uploads/2015/12/MLMDigest.pdf

Harney, L., McCurry, J., Scott, J., \& Wills, J. (2016). Developing "process pragmatism" to underpin engaged research in human geography. Progress in Human Geography, 40, 316-333.

Heller, M. (2011). Paths to post-nationalism. A critical ethnography of language and identity. Oxford: Oxford University Press.

King, L. (2015). Multilingual cities and the future: Vitality or decline? In L. King \& L. Carson (Eds.), The multilingual city: Vitality, conflict and change (pp. 179-202). Clevedon: Multilingual Matters.

Leggio, D. V. (2017). Critiquing stereotypes: Research engagement with local authority interventions in support of Roma migrants. ANUAC, 6(1), 119-140.

Lucas, S. E. (2016). Interpreting: One size fits all? English language as an essential component of social work. In C. Williams \& J. G. Mekada (Eds.), Social work in a diverse society: Transformative practice with black and minority ethnic individuals and communities (pp. 91-108). London: Polity Press.

Malinowski, D. (2016). Localizing the transdisciplinary in practice: A teaching account of a prototype undergraduate seminar on linguistic landscape. L2 Journal, 8(4), 100-117.

Matras, Y. (2017). Can global cities have a language policy? Languages, Society \& Policy, 1(1). Retrieved from http://www.meits.org/languages-society-policy

Matras, Y., \& Leggio, D. V. (2017). Community identity and mobilization: Roma migrant experiences in Manchester. In Y. Matras \& D. V. Leggio (Eds.), Open borders, unlocked cultures. Romanian Roma migrants in Western Europe (pp. 151-170). London: Routledge.

Matras, Y., \& Robertson, A. (2015). Multilingualism in a post-industrial city: Policy and practice in Manchester. Current Issues in Language Planning, 16(3), 296-314.

Matras, Y., Robertson, A., \& Jones, C. (2016). Using the school setting to map community languages: A pilot study in Manchester, England. International Journal of Multilingualism, 13, 353-366.

MigRom. (n.d.). Retrieved from http://migrom.human ities.manchester.ac.uk

Multilingual Manchester. (n.d.-a). Reports. Retrieved from http://mlm.humanities.manchester.ac.uk/ reports

Multilingual Manchester. (n.d.-b). LinguaSnapp. Retrieved from http://mlm.humanities.manchester.ac. uk/linguasnapp

Multilingual Manchester. (n.d.-c). Volunteering. Retrieved from http://mlm.humanities.manchester.ac. uk/volunteers

Multilingual Manchester. (n.d.-d). The dialects of Kurdish. Retrieved from http://kurdish.humanities.man chester.ac.uk

Multilingual Manchester. (n.d.-e). The dialects of Arabic. Retrieved from http://www.arabic.humanities. manchester.ac.uk

Multilingual Manchester. (n.d.-f). Living in a city of languages. Retrieved from http://mlm.humanities. manchester.ac.uk/living-in-a-city-of-languages

Multilingual Melbourne. (n.d.). Retrieved from http:// arts.unimelb.edu.au/rumaccc/community/multilin gual-melbourne

Multilingual Graz. (n.d.). Retrieved from http://multilin gual.uni-graz.at

Patrick, P. L. (2012). Language analysis for determination of origin: Objective evidence for refugee status determination. In L. Solan \& P. Tiersma (Eds.), The Oxford handbook of language and law (pp. 533-546). Oxford: Oxford University Press.

Peck, J., \& Ward, K. (Eds.). (2002). City of revolution. Restructuring Manchester. Manchester: Manchester University Press.

Pennycook, A., \& Otsuji, E. (2015). Metrolingualism: Language in the city. London: Routledge.

Piller, I. (2016). Linguistic diversity and social justice. An introduction to applied sociolinguistics. Oxford: Oxford University Press.

Rampton, B. (2015). The next ten years for applied linguistics? (Working Papers in Urban Languages \& Literacies 165). London: King's College. Retrieved from http://kcl.academia.edu/WorkingPapersinUrbanLan guageLiteracies

RCUK. (n.d.). Pathways to impact. RCUK. Retrieved from http://www.rcuk.ac.uk/innovation/impacts

Sassen, S. (2005). The global city: Introducing a concept. Brown Journal of World Affairs, 11(2), 27-43.

Schiller, M. (2016). European cities, municipal organizations and diversity: The new politics of difference. Basingstoke: Palgrave Macmillan.

Shek, D., \& Hollister, R. (Eds.). (2017). University social 
responsibility and quality of life. A global survey of concepts and experiences. Berlin: Springer.

Stevenson, P. (2017). Language and migration in a multilingual metropolis: Berlin lives. Houndmills: Palgrave Macmillan.

Syrett, S., \& Sepulveda, L. (2011). Realising the diversity dividend: Population diversity and urban economic development. Environment and Planning, 43(2), 487-504.

Tietze, S., Holden, N., \& Barner-Rasmussen, W. (2016). Language use in multinational corporations: The role of special languages and corporate idiolects. In V. Ginsburgh \& S. Weber (Eds.), The Palgrave handbook of economics and language (pp. 312-341). Houndmills: Palgrave Macmillan.

Williams, G. (2003). The enterprising city centre. Manchester's development challenge. London: Spon Press.

Young, C., Diep, M., \& Drabble, S. (2006). Living with difference? The 'cosmopolitan city' and urban reimaging in Manchester, UK. Urban Studies, 43, 1687-1714.

\section{About the Authors}

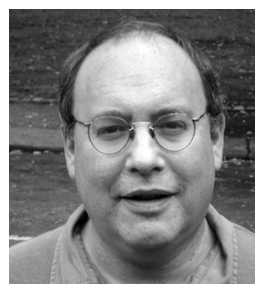

Yaron Matras is Professor of Linguistics at the School of Arts, Languages and Cultures at the University of Manchester. His areas of research specialisation are contact linguistics, minority languages, languages of the Middle East, and language documentation. He is the founder of the Multilingual Manchester research unit at the University of Manchester.

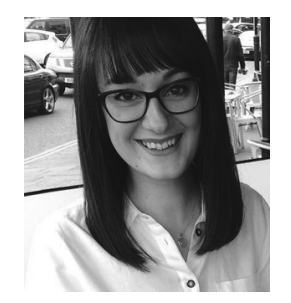

Alex Robertson holds a degree in French and English Language and has worked as research assistant, and is now project manager on the Multilingual Manchester research unit at the University of Manchester. 